\title{
Serious Game Design For Playful Exploratory Urban Simulation
}

\author{
Lan $\mathbf{V u}^{a, *}$ and Sheng-ming Wang ${ }^{b}$ \\ ${ }^{a}$ Doctoral Program in Design, College of Design, National Taipei University of Technology, \\ No. 1, Section 3, Zhongxiao East Road, Da'an District, Taipei City, Taiwan \\ ${ }^{b}$ Department of Interaction Design, National Taipei University of Technology, \\ No. 1, Section 3, Zhongxiao East Road, Da'an District, Taipei City, Taiwan \\ E-mail: kennyvulan@gmail.com, ryan5885@mail.ntut.edu.tw
}

The year 2020 has stricken humanities with the ferocious COVID-19. During this period, regulation and restriction are active to mitigate the spread while simultaneously causing massive behavioral change globally. While the post-pandemic situation has created new habits, rules, and limitations to restrict traveling, it also offers opportunities to introduce the citizens an interactive technology solution to explore their urban space and neighborhood effortlessly and risk-free. This paper proposes the use of Minecraft, a sandbox game, and its gameplay to design an interactive serious game-based platform for collaborative urban exploration in a playful, immersive approach. The prototype within this paper applies the digital twin concept and its principles for the realistic re-creation of a virtual Dihua Street of Dadaocheng, an old town and a tourist hotspot in Taipei, Taiwan. In a serious-game environment that is both a playground and a working platform, users can cooperate with others, create dynamic user-generated content. As they explore while sharing their knowledge and experience in the virtual open space, users are also engaged in serious urban planning tasks. This paper's main objective is to present the preliminary data of top priority users' satisfaction with game elements or features to develop a serious game-based urban exploration platform while demonstrating the proof-of-concept of the urban digital twin.

International Symposium on Grids \& Clouds 2021, ISGC2021 22-26 March 2021 Academia Sinica, Taipei, Taiwan (online)

${ }^{1}$ For the ISGC2021

${ }^{*}$ Speaker 
Keywords - Minecraft, Digital twin, Serious game, Playful design

\section{Introduction}

In 2020, the globe was struggling against the novel coronavirus pandemic (COVID-19). Regulation and restriction are active for virus spread mitigation, but consequently, humanity cannot return to the "normal" before, switching from being socialized to social distancing, demanding a more contactless strategy. In this period, there has been an increase in screen time significantly for activities on TV, smart mobile devices and video game consoles [11], [12], [39]. From this post-pandemic behavior, it seems that this is an opportunity to introduce the users a technological solution for exploring the area around them or the ones of a distant nation. Through providing a virtual urban exploration experience, users can have an overall view of the area, become more aware of its space and the attentive places. This service combines the concept of digital twin for the realistic replica and Minecraft, a sandbox game, as a factor for motivating the participation.

The digital twin;s basic is to create virtual twins of physical ones for monitoring, diagnostics, predicting product life cycle while serious games main objective is to create game-based learning that promotes learning through game entertainment. A digital twin concept in a serious game-based platform allows users to contribute their knowledge, practice modeling skills and eventually predict sustainable smart city development through cost-efficient, risk-free interaction and accuracy in achieving results. Serious games also have the ability to influence one's motivation, engagement and increase in civics participation [4],[3],[19],[28]. The civics participation, including the locals and those who are interested in urban exploration on such platforms help them understand the complex urban issues. The design of a collaborative serious game can be cracked down into multiple levels of emotional state besides the visual elements while linking to the domain of learning skills [6]. The formation of video gaming experience varied from positive to negative emotion which is carved into users' emotional memories and those in the gaming world that make it more enjoyable [37].

A criticism for a serious game is that it would suspend its playfulness if it is too serious and if players are too immersed, they likely ignore the expected learning outcome. Likewise, if the digital twin is not realistic enough, users would not get the experience of being there. Hence this paper explores the basic elements for the development of a playful, collaborative serious-based gaming platform that facilitates learning. This paper is organized as follows. The next part reviews literature of the post-pandemic situation, the digital twin concepts, serious games, and Minecraft. This paper first reviews the new situation during post-COVID-19 and the digital twin concept and principles then explores the serious games-related research and finally Minecraft-related literature.

After the literature review, this paper continues with the research design process through the design thinking of emotional design to bring forward user-centered game elements and features After the analysis step, this paper follows up with the proof of concept - the prototype. Carry on with the analysis part, this research proceeds to evaluate users' satisfaction with the game features and elements using the Kano Model. The result justifies key game elements or features to focus on while showing those to let go. The last part of this paper includes the conclusion and future works.

\section{Literature Review}

\subsection{The digital surge during post-pandemic}

At the period of the post-COVID-19 pandemic, although the pandemic has stabilized in some countries, its new variants' re-emergence is spreading wildly and swiftly [9]. Humanities have learned to live with it at the time of writing, although there are still distresses due to cases detected daily, even for countries like Taiwan [36]. Previous studies implied the reason for the new cases are due to international tourists and workers who are infected after airplane travel or contacting those who have just arrived [23],[24]. However, 
besides the demand to leave home due to the travel restriction, people are now taking more internet-based services to work, communicate, and relieve stress [12],[39]. Domains such as education are now switching to online while organizations are starting to adopt technological solutions from technologies such as Cloud Computing, the Internet of Things (IoT), Blockchain, Artificial Intelligence (AI), and Machine Learning in their digital transformation effort [12].

The pandemic situation has transformed the world where people get excluded if they have difficulty with technology adoption. The social distancing measures have brought people to new activities and routines that are internet-dependent. Although the new situation has brought the world to a situation full of uncertainty that inflicts stress and fear, digitalization also increases online fraud and security breaches. One good example relates to the use of Zoom during the pandemic for online meetings and classrooms as hackers can easily access users' personal information [12]. Consequently, from the zoom case, technology such as Blockchain was able to stand out as it created a secure and safe information management system. Similarly, the travel restriction and the surge of digitalization present the opportunities to introduce a technology solution for citizens to explore virtual space, a space that is a digital twin of an actual destination.

\subsection{Digital Twin principles for a collaborative urban virtual space}

The global fourth industrial revolution (Industry 4.0) includes the technical processes to reduce human intervention as much as possible. One of the processes involves digital transformation, and this area confronts the digital innovation to uptake and further support the growth of sustainable urban development while discovering the linkages between data and urban challenges for Smart City.

The pandemic's impact requires a new insight into the city and the public spaces effortlessly and riskfree. Social distancing requires everyone to stay home during the pandemic, but it is unlikely for people to do it permanently. There is a connection between the cities' density and the virus' spread [20],[21] and at specific points, it is inevitable to encounter a passerby with the virus while passing a narrow road. The digital transformation integrates digital technology into multiple areas and conceptualizes a new technical integration for digital information representation and management of a city such as digital twin.

Digital twin's definition is varied from different domains and literature but still identical in digital data representation [13],[15],[30],[38]. NASA first brought the digital twinning concept. Its processes involved the integration of multi-physical, complex multiscale probabilistic simulations of real object models to obtain its accurate digital representation based on data and other sources [14],[35],[38] or to be concise; digital twin is a digital replica of a living or nonliving physical entity [15]. The application of a digital twin allows data analysis and systems monitoring of systems to plan for prediction through simulations [9], simulate feasible options, and identify the benefits and drawbacks before real-world implementation.

The uncertainty has expanded the digital twin's boundaries to the urban environment in the post-COVID19 period, creating the spatial digital twin concept for delivering the city as a collaborative platform. An excellent example of such platforms is from the case study of Herrenberg Town, German [14], and Zurich city [34]. These platforms are made publicly available online to support citizens with communication, model interaction, leaving feedback and decision-making about urban planning decisions. Geodata expansion within a digital twin system encourages location-based cooperation of the system members, from internal to externals [34]. One example is for those interested in real estate or urban development, and they can interact to have a whole picture of the area.

An ideal smart city digital twin models depend on the layers of data to deliver a better outcome. However, the accurate representation and the association of realistic details is another critical element of a digital twin. This element is based on multiple data, and for instance, the Spatial Information Council ANZLIC [5] came up with the principles for spatial digital twin (Figure 1): 


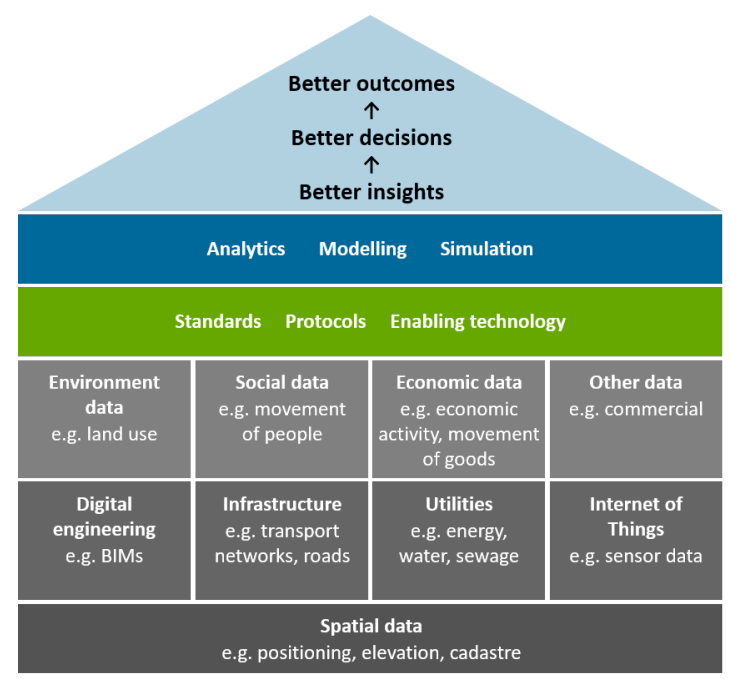

Figure 1: Principles for Spatially Enabled Digital Twin by ANZLIC

Note. The image was created from a strategic planning session to represent Digital Twin Principles. From ANZLIC. (n.d.). Principles for Spatially Enabled Digital Twins of the Built and Natural Environment in Australia. https://www.anzlic.gov.au/resources/principles-spatiallyenabled-digital-twins-built-and-natural-environment-australia

From Figure 1, a digital twin platform may require data such as environment, social, economic, infrastructure, digital engineering, utilities, and even the Internet of Things. The analytics of digital twin systems is based on its modeling and simulation; thus, digital engineering tools or building information systems (BIMs) are needed. IoT allows the digital twin to constantly update itself data required for the Smart Cities, leading to an increase in its complexity. An advantage of digital twins is simulating a scenario and forecasting a city's sustainable development. It can illustrate the socio-spatial interferences and the unpredicted drawback of social distancing in the long term to the urban space. For instance, people avoiding crowds and movement restrictions could lead to the decline of public transit, affecting future urban planning.

\subsection{Serious Games}

Serious game is a combination of using entertainment to achieve educational goals. [2]. As a game, serious games are considered to be games that have learning benefits besides the value of entertainment. While serious games are described as an influencing tool for learning, to evaluate a video game, its playability, or its quality of gameplay is an elusive factor yet critical to determine the gaming experience. The fundamental of learning is by playing. Play as a social form is crucial for knowledge development and insight of the world [22]. Learning to cooperate and negotiate promotes critical social skills [40]. As a constructivist pedagogical strategy, serious game-based solutions can engage the learner, provide opportunities to explore, challenge and raise awareness of a problem [26],[29]. There are reasons that motivate people to play video games such as escaping reality and enjoying the social relationship in the virtual world [37].

Serious games-related research has been rising in recent years. In most serious games-related literature, researchers tend to focus on the game making or adding game elements and leave the fun or playful elements. Serious tasks like urban planning often relate to politics, and only the superiors can access them. There are serious games-related researches that promote the collaboration between players through urban participation and transform serious tasks such as urban planning "playful". To achieve the playfulness, the first step is to make the environment smart, and the citizens living in such an environment can become smart in response. The reason for serious games' application is its influence on one's emotional state. As an entertainment 
activity, video gaming is capable of forming different states of emotion, from positive to negative like happiness and sadness. However, most research tends to focus on evaluating the interface design and ignore the emotion, the motivation for playing games. Only a few noticed this and for instance there are researchers who investigated the relation of the Don Norman's three-level emotional design with the domain of learning while developing a framework of emotional design for games [6] (Figure 2). From this framework, this research designs and analyses the game elements and features in the corresponding emotional level.

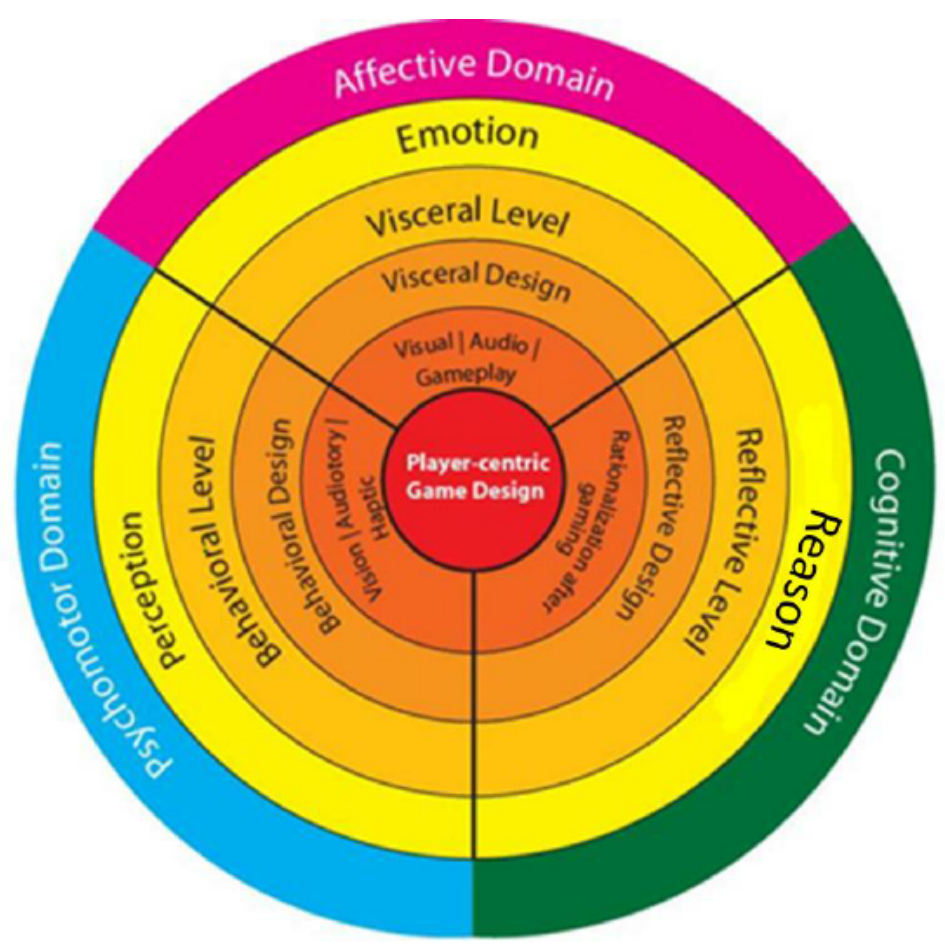

Figure 2: Conceptual framework of emotional design for games by Baharom 2014

Note. The image was created to present the framework of three-levels of emotional design for games. From Baharom, S. N., Tan, W. H., \& Idris, M. Z. (2014). Emotional design for games: A framework for player-centric approach in the game design process. International Journal of Multimedia and Ubiquitous Engineering, 9(10), 387-398. 


\subsection{Digital Twin co-simulation with serious games}

A co-simulation could open the possibilities of knowledge acquisition, training, or designing in dynamic virtual environments through real-time data exchange. For that reason, digital twin should integrate within another context such as a serious game for motivating users participation while having Minecraft as the base, the BIMs to visualize the urban area for exploration in gaming environments that can integrate the data from the spatial, environment, infrastructure as well as social data to deliver a better simulation and better outcomes.

As a form of modern media, serious game content creators can deliver remote, accessible, and immersive gaming content for acquiring knowledge. Throughout the evolution of media contents, immersion or the sense of presence (SoP) is the key for VR technology [7]. The pandemic might have prevented people from physically attending a location, but by giving them the SoP, it is possible to make them immerse in the virtual environment. The SoP can be divided into social presence and spatial presence [30]. While the social presence is about how users experience being there with technology-enabled, the spatial presence is the technology enhancement of SoP in a virtual environment.

Regardless, with the digital twin concept, this research recreates the virtual models of physical location in a serious game. As users explore the virtual area, they can experience the fun of exploring and immerse in a playful approach. However, most of the literature uses VR technology and there are multiple downsides of this technology in the past decades that are listed in Table 1. Additionally, its controlling techniques mainly depend on either touch input or head tilt and interrupt users' interaction flow.

\begin{tabular}{|c|c|}
\hline Traditional Immersive Experience & Playful Immersive Experience \\
\hline Fixed visual content & Dynamic visual content, content improved, renewed at all time \\
\hline Lacks of interaction & "Play" as interaction \\
\hline Mostly VR & VR, PC, Game consoles \\
\hline Individual virtual platform & Virtual platform for co-working, co-sharing \\
\hline Designer do everything & Everyone work together as a platform \\
\hline
\end{tabular}

Table 1: Comparison the immersive experience

\subsection{Minecraft serious game}

Minecraft, a sandbox game is one of the platforms that employ modeling as its gameplay feature. Although Minecraft itself is a game, its modifiability enables researchers from different backgrounds such as designers, engineers, educators, and many more to develop serious game contents. By utilizing its gameplay; having a pixel-like block to block world-building, it acts as a BIM that allows players to construct almost anything freely and creatively in a 3D environment.

The game itself is divided into two main modes: Creative and Survival. In Survival, players gather resources to craft blocks and build structures. In this mode there are hidden rules they need to follow in order to fight forces to survive, and explore new areas. In Creative, they have unlimited resources to build their imaginative world. Regardless of which mode they chose, players are forced to use creativity and imagination every time they play. Players can show their creativity to create contents that can train and educate others on how to perform and quickly adapt to their current situation in a creative approach [17]. Students can learn necessary skills for the 21 st-century, such as leadership, navigation, innovative thinking, and problem-solving skills, which can be used in virtual and physical worlds [21].

Minecraft also promotes children to learn programming. There are researchers who tested the server performance control with Minecraft [10]., for developing machine learning such as MineRL [32], for teaching coding on Code.org with walkthrough methods to create a task-oriented, outcome-driven platform in beginner 
level programming [18]. With its gameplay characteristic, Minecraft's ability for modeling and its geo game characteristics makes it qualify to be implemented as a research tool to engage participants with urban planning processes [16]. In the case study of Austria, the researchers explored its usability as a scenario geodesign tool to motivate public participation in urban planning decision support thus it is related to the aim of a gamified simulation. In another literature, through the application of the Geo-ICT framework, they develop their own version called Geocraft to provide information for the forming of future smart cities [33].

As a game, Minecraft is popular among the young age group. It focuses on engaging children, the future adults or the future inhabitants of the public space. With simple spatial logic, it encourages them to work together, play together in a co-constructing environment and simulate complex, challenging scenarios, which can be playfully attractive to them. Therefore, the inclusion of Minecraft serious games into this platform can teach spatial science and challenge the next generation with urban planning to help build a sustainable city during pandemic crises. Furthermore, as a modern era media, it can ensure scientific and technology literacy to fight against the misinformation of COVID-19. Undoubtedly, Minecraft's value can expose the risk and determine the development as well as the recognition needed to strengthen public health and as a game, capable of immersing its users in virtual exploration.

\section{RESEARCH DESIGN}

\subsection{Three Levels of Emotional Design By Don Norman}

The design of a game is a co-creation process that correlates the gamers and the game designers. This interconnection plays an important role as the players are the consumers playing the game, and the designers are the providers of the social environment and in-game situations to challenge them. From another direction, a serious game is a game, but the design approach would be different from a regular game. As its goal is to educate, train, or to sum up, providing knowledge, a player may enjoy a serious game with more challenges than the one with no challenge at all design. Instructional design approach enables the teaching but at the same time, having too much instruction could remove the playfulness of a game due to the lack of opportunities to experience and interact with knowledge. Contrarily, this paper proposes adopting Don Norman's design theory on emotional design and its connection with the three learning domains based on the framework explored (Figure 2) [6]. This paper explores a broader sense of learning through playing as the interaction that involves the acquisition of knowledge, skills and the formation of attitudes based on Baharom's work (Table 2). 


\begin{tabular}{|c|c|c|}
\hline Level of Emotional & Relation to products & Domain of Learning \\
\hline Visceral & $\begin{array}{l}\text { - First visual/auditory impres- } \\
\text { sion upon entering the virtual } \\
\text { world. }\end{array}$ & $\begin{array}{l}\text { Affective (Emotional, in- } \\
\text { terpersonal development) }\end{array}$ \\
\hline Attractiveness: & $\begin{array}{l}\text { - How does it look and feel? } \\
\text { (Emotional consciousness of the } \\
\text { game appearance elements ) }\end{array}$ & \\
\hline Initial Instinct Impression & $\begin{array}{l}\text { Memory emotional cognition } \\
\text { to the recognition of location }\end{array}$ & \\
\hline Behavioural & $\begin{array}{l}\text { - The enjoyment through game } \\
\text { elements manipulation }\end{array}$ & $\begin{array}{l}\text { Psychomotor (Physical in- } \\
\text { teraction) }\end{array}$ \\
\hline Usability: & $\begin{array}{l}\text { - Does it function well? Is it } \\
\text { easy to use and reliable? }\end{array}$ & \\
\hline $\begin{array}{l}\text { Effectiveness of use in the } \\
\text { shortest time, with fewest } \\
\text { actions }\end{array}$ & & \\
\hline Reflective & $\begin{array}{l}\text { - Reflection of the users in rela- } \\
\text { tion to the location brand. }\end{array}$ & $\begin{array}{l}\text { Cognitive (Thinking, } \\
\text { problem solving) }\end{array}$ \\
\hline Conscious thought: & $\begin{array}{l}\text { - Creating appreciation, mak- } \\
\text { ing emotional connection with } \\
\text { the environment and other peo- } \\
\text { ple they work with }\end{array}$ & \\
\hline Meaning of product & & \\
\hline Sharing experience & & \\
\hline Cultural meaning & & \\
\hline
\end{tabular}

Table 2: Connection between three-level emotional design and Three Domain of Learning to game elements based on Baharom 2014

Note. This table was created based on The Connection between Three Levels of Emotional Design and Three Domains of Learning in Relation to Six Structural Elements of Game Table by Baharom to present a comprehensible definition of the three levels of emotional design. From Baharom, S. N., Tan, W. H., \& Idris, M. Z. (2014). Emotional design for games: A framework for player-centric approach in the game design process. International Journal of Multimedia and Ubiquitous Engineering, 9(10), 387-398.

This paper aims to define a serious game platform elements where users can join in one virtual world to cooperate. This serious game would promote the co-work and co-share ability using Minecraft gameplay to create dynamic content effortlessly and explore them together. As a game, users can control their virtual character to freely move in this 3D environment and enjoy the virtual blocks architecture models others created that is sufficiely realistic to the physical models. Users with limited creativity can still learn from others and help them rebuild, improve this virtual world together. As a result, users can feel rewarding or achieving as they build something they could not in the real world. Through the representation and story, users can recreate a real-world scenario and bring it to the virtual world to deliver a message so others can raise their situation awareness. Moreover, as a spatial exploring platform, this product can enable users' spatial awareness of a location they had never visited before by helping them locate in the digital twin of a 
physical destination and enhance their visual and auditory experience.

The design theory of Don Norman on emotional design can determine the game elements and features with corresponding emotion levels. Serious games benefit players with emotional connections in the postpandemic situations, especially when a virtual world of video games can simulate scenarios to raise their situation awareness. In "Emotional Design: Why we love (or hate) everyday things", Don Norman, an academic in the field of cognitive science, design, and usability engineering, categorizes three different complex but still relatable levels of the emotional system. He believes that when one judges the overall design, they tend to depend on their visceral, behavioral, and reflective level of the emotional system. While visceral is the unconscious reaction, which is sometimes uncontrollable, behavioral is the controlled part that leads to an outcome-driven strategy to deal with a situation effortlessly, and reflective level is where users have insight, the meaning behind the design of an object. Based on these three levels, a design can deliver better results within the context of HCI and UCD.

\subsubsection{Visceral Design}

"Visceral design concerns itself with appearances" [25]. The initial perspective of this level of design relates to the first impression of the product, which determines the way users perceive and have feelings toward it. The first characteristic of Minecraft and its similarity to the world of VR is the 3D environment. The 3D environment from most VR software is for showcase, and the space is limited. On the other hand, the 3D environment in Minecraft is a playground where everyone can interact with an infinite terrain, discover and extract multiple kinds of materials, craft tools, and build structures. The visceral design could rely on the models, the materials, the color where users find its details close to the real-world models. The data and technology in this phase and the creativity displayed in this 3D environment are the real world's geoinformation that can trigger their awareness of space. Users in this virtual world space can gain the relationship between the environment and their emotional needs, such as their attitudes, beliefs, and how they want to express their emotional responses to space affect their knowledge acquisition process and their immersive experience.

Although Minecraft itself is already a game, there are hundreds of choices when modifying it to enhance users' experience, such as giving them more choice of decorative items or gameplay options that the original game could not offer. As a result, the entire game can become more serious and fun as it provides a visual and auditory quality enhancement to pick up their interest. Additionally, paying attention to even the minor detail in the design, including the choice of color and material, can trigger their emotional memory cognition while giving them features such as a Mini-map that can help them navigate and distinguish the difference as they explore the virtual world. Essentially, the experience that this platform offers to make them more motivated can include systems such as the quest, reward, and achievement to stimulate their willingness and curiosity for self-learning.

\subsubsection{Behavioral Design}

"Behavioral design has to do with pleasure and effectiveness of use" [25]. The behavioural design process can be described as a guide to use the product. Without knowing what to do next, the product is likely to fail so the game elements and features in this process is like a journey where the designers have to analyze until the users can reach the goal. As the middle level of the three-levels emotional, behavioral design is a process that the guideline, the experiencing of a product plays its role the most.

The experience of a product relates to its function, performance, and usability. The function of a product is the purpose it is used for while its performance is how well it deals with these purposes in order to reach the desired outcome. The usability part is how easy a user can understand to make a product work. All and all, from this level perspective, when users enter the world of a game, they would expect the fun while performing a distance travel of a place they have or have not visited with less effort and risk-free due to the post-pandemic situation. In the post-COVID-19 situation, new behaviors for traveling such as wearing a 
mask at all times, keeping a distance from one another creates more work and causes frustration and negative emotion to users' experience. Therefore, in this serious game for urban exploration, it is optional to remove these behaviors and bring users back to the Normal before to optimize the fun and so they can focus on exploring without any restriction.

Besides the set of rules and the environment design, this platform should anticipate the gameplay to utilize the acquisition of knowledge and training while users are able to explore it freely with the output device control. Minecraft's gameplay is simple but still requires skills to keep experiencing it without any interruption. In other researches of Minecraft, one of the reasons for it to inspire children to learn programming is its list of commands and cheats. As a co-creation platform, both designers and users can share their creations so that those who lack skill can also use them, although they need to learn the commands or the cheat codes to use these user-generated contents eventually.

\subsubsection{Reflective Design}

"Through reflection, you remember the past and contemplate the future" [25]. The last and the highest level of emotional design, reflective design is one complex system based on culture, experience, education, and many other elements, including time and fear. As a result, it may override the other two levels as some may find a design appealing, but others may not. The previous two levels are about affective and no insight nor awareness. From another example by Don Norman, the immediate and positive response of visceral level conflicts with reflective level by triggering users' reflective level to think about the past, from "the good old days" experiences to the negative ones. They would remember the scenario and how badly they perform that would waste their precious hours but still cannot complete the goal. By giving a different meaning, purpose, reflective design can deliver the power of seeing into a situation intuitively and knowledge acquisition in the long term.

Don Norman acknowledges the game capabilities as "a learning and educational tool for people of all ages" and "a source of simulation, experiments and extensive exploration of interesting, well-motivated topics" where users can "attend deeply and seriously for hours, weeks, even months" [25]. From the game perspective, Minecraft and the digital twin concept can potentially re-create scenarios, telling stories and reflect the current social problems during the post-pandemic in a public collaborative environment for acquiring knowledge. However, in the reflective design, the key element is the users gain the meaning of the products or the insight to it. Minecraft is both an offline and an online game but if the contents were for one person to experience at one time, it would not only lose the fun but also not help that single user recognize the actual value due to differences in users' reflective level. On the other hand, if the contents are made available online, publicly for multiple users in Minecraft multiplayer mode, users can experience this urban exploration platform at once. Together, users are able to exchange their knowledge and insight as they collaborate, co-share, build and enrich this virtual world. The outcome of their cooperation allows them to achieve credibility results through training and compared to the traditional training methods, users are allowed to fail in a simulation and can retry constantly. Consequently, they gain better insight and knowledge throughout their retries and in relation to the visceral level, they gain.

From the design analysis of Don Norman's three-levels emotional design, this paper is able to draw out several game elements and features to design a serious game-based urban exploratory platform (Table 3) 


\begin{tabular}{|c|c|}
\hline Level of Emotional & Features/Elements \\
\hline $\begin{array}{l}\text { Visceral } \\
\text { (Simple/ Basic design that } \\
\text { interest users) }\end{array}$ & $\begin{array}{c}\text { - 3D environment for visiting } \\
\text { - Visit destinations inside Minecraft } \\
\text { - Details close to real models } \\
\text { - Mini-map } \\
\text { - Quest, Reward \& Achievement System } \\
\text { - Extra decorative items/ options } \\
\text { - Visual quality enhancement close to realistic } \\
\text { - Dynamic auditory surrounding enhancement }\end{array}$ \\
\hline $\begin{array}{l}\text { Behavioural } \\
\text { (The guide to use the prod- } \\
\text { uct and what to do next) }\end{array}$ & $\begin{array}{c}\text { - Risk-free interaction } \\
\text { - Distance travel while at home } \\
\text { - Virtual explore at any time } \\
\text { - Output device control to move in virtual world } \\
\text { - Move instantly cheat code } \\
\text { - Placing building instantly cheat code }\end{array}$ \\
\hline $\begin{array}{l}\text { Reflective } \\
\text { (Self-image and message } \\
\text { sending to users) }\end{array}$ & $\begin{array}{c}\text { - Scenario, Storytelling, Social problem reflection } \\
\text { - Multiple people visit together/Multiplayer } \\
\text { - Co-work, co-share to build/rebuild/decorate virtual models }\end{array}$ \\
\hline
\end{tabular}

Table 3: Corresponding emotional levels of game elements and features

\section{Proof of Concept}

\subsection{Digital Twinning Process}




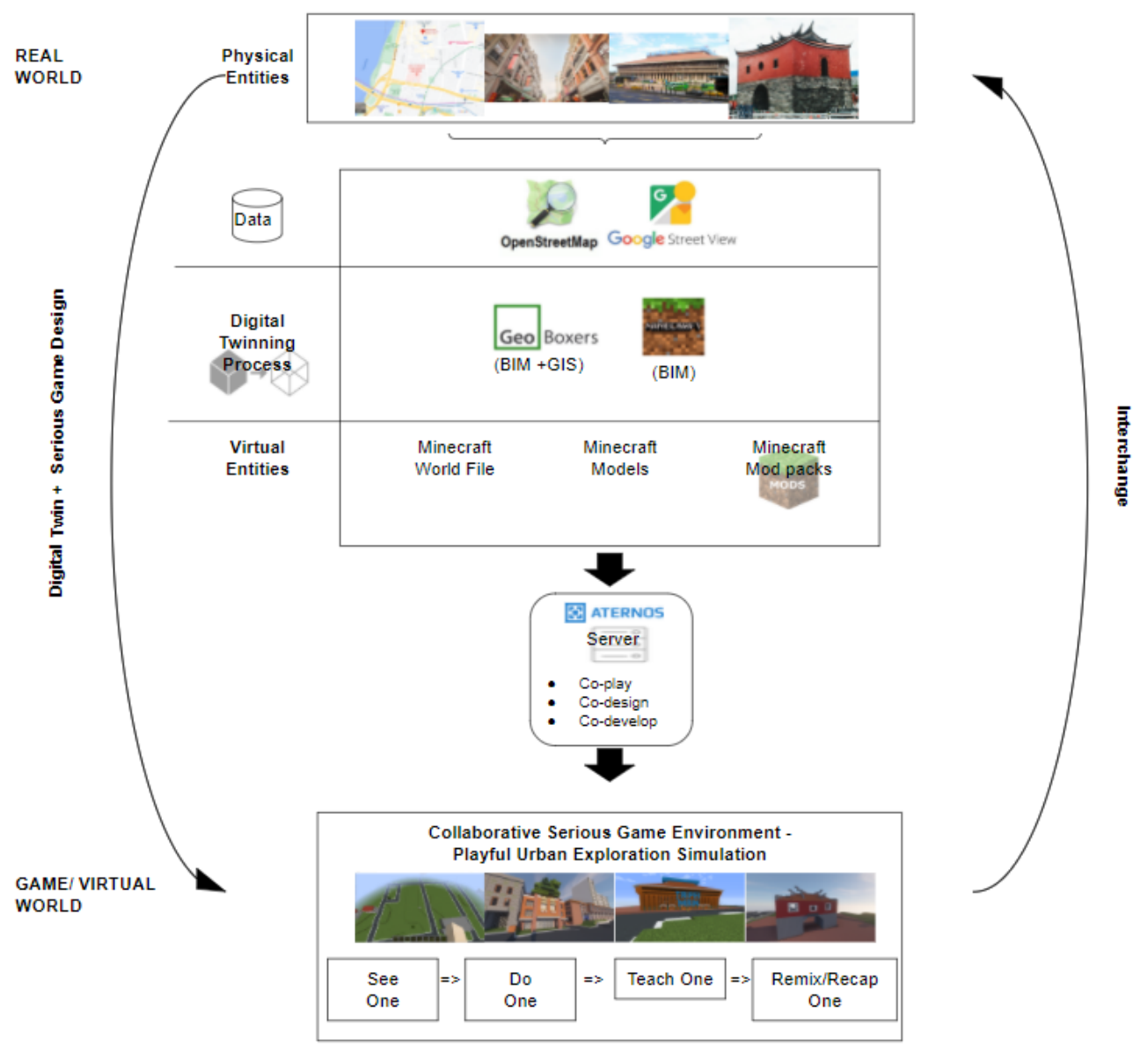

Figure 3: Collaborative simulation workflow and interchangeable between virtual - physical world.

The Figure 3 explains the workflow of the making of this collaborative simulation. In the digital twinning process, this research uses environment, infrastructure data and spatial data obtained from OpenStreetMap (OSM) and Google Street View to recreate the virtual twin of Dihua Street, Dadaocheng area, and two near special landmarks: Beimen and Taipei Main Station. It can be seen that several tools are involved for transforming the data into the digital twin. Each of them has their own usage and weaknesses as they do not have the same features except the creation of objects within Minecraft. After the Minecraft world is generated and materials prepared, it will be uploaded to a server, and for this paper, Aternos, a free server provider for Minecraft that also provides an interface for management. Once the world is set, users can join through the multiplayer mode after typing the server IP address. Users can see the virtual objects, create one through the Minecraft unique gameplay through learning by themselves or from the others. They are also allowed to remix, recap the objects and manipulate them at will. The admin can restrict behaviors that could cause unpleasantness from the Aternos management tool.

\subsection{The Environment, Street Pattern and Occupied Architectures}

The environment digital twinning process involved a paid-service called GeoBoxers, which integrates GIS data from OSM for map creation within the given box (Figure 4). Within minutes, the outcomes are outstanding as the street pattern, the architectures are well-present (Figure 5). However, the other flaw 
besides the limitation of the area box is that if OSM lacks data then GeoBoxers cannot create the occupied architectures.

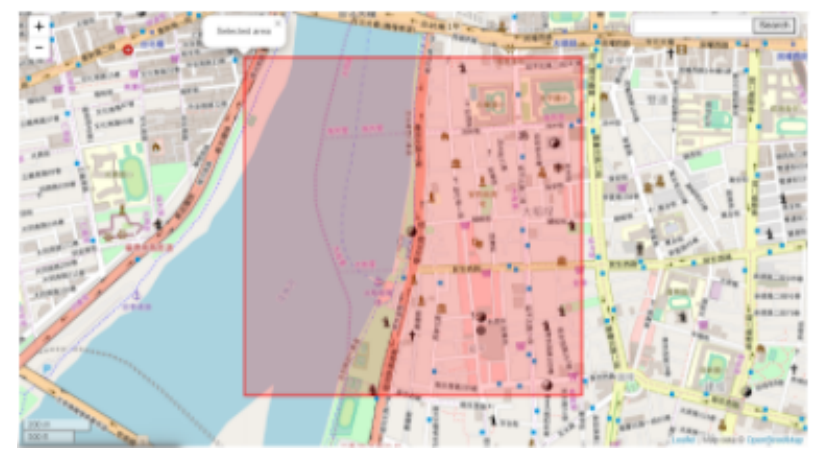

Figure 4: GeoBoxers box for map creation
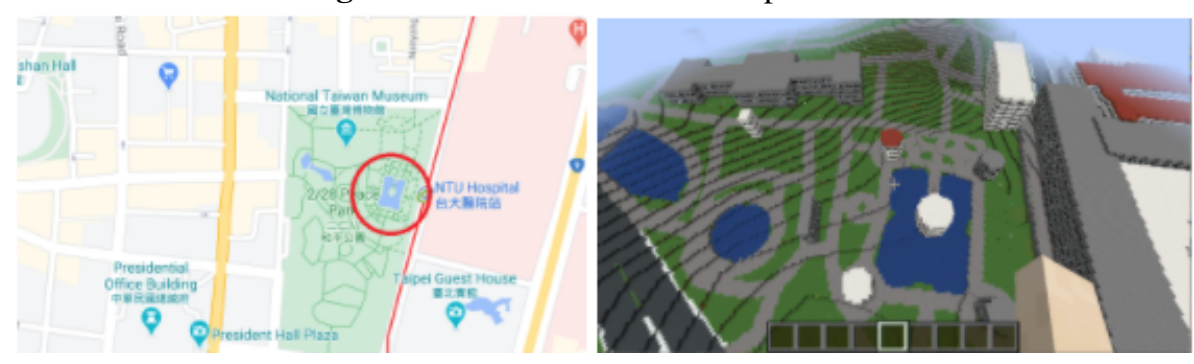

Figure 5: Street pattern and architectures generated from Geoboxers

\subsection{Special architectures and reusable ones}

With the assistance from GeoBoxers, a map of an area can be generated with ease. Still, the architecture models generated from the service lack details while the recognition of important landmarks are crucial as it helps users locate where they are. There are two approaches to carry out the architecture creations. The first one involves actual 3D modelling skills and the use of a 3D model conversion tool to convert the models into Minecraft models such as Tinkercad. The second approach involves the actual gameplay of Minecraft which is by placing blocks by blocks. Both methods are time consuming and the first approach might not be the best option as the result attains the shape but lacks in details. The second approach helps build more detailed ones but for extensive models it could take even more time. The comparison of two approaches is presented in (Figure 6). 
Physical Model

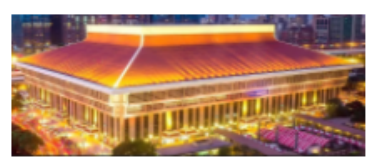

Conversion Approach

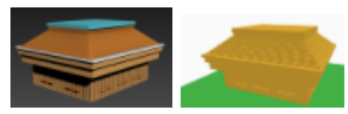

Build through gameplay approach

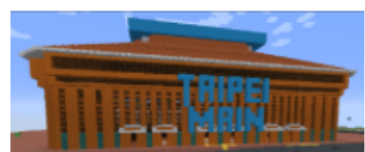

Figure 6: Street pattern and architectures generated from Geoboxers

Be that as it may, the weakness of the second approach can be overcome through modification packages (mod packs) such as WorldEdit. This type of mod packs extend the Minecraft gameplay by adding more features or functionalities for quick construct or deconstruct of a model. It is also a solution for reusable architecture and the key for recap, reuse and replace a model. The results for other special architecture and how detailed they could achieve through the second approach are presented in (Figure 7).

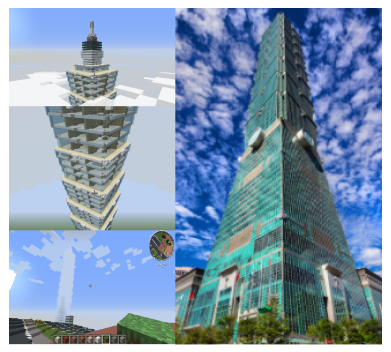

(a) Digital Twin of Taipei 101 in Minecraf

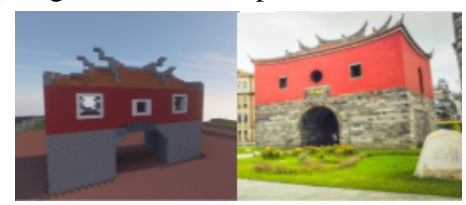

(b) Digital Twin of Beimen in Minecraft

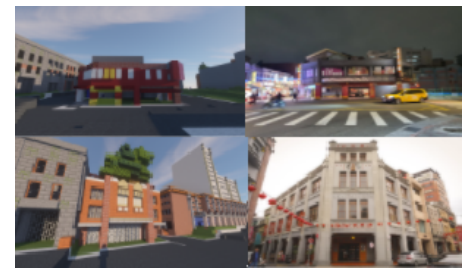

(c) Digital Twin of Dihua Street, Dadaocheng in Minecraft

Figure 7: Digital Twins of special landmarks 


\section{Research Evaluation and Discussion}

\subsection{Kano Model}

From another perspective, the three-layers of emotional design links to the quality of products such as functionality, reliability, and usability. However, design veteran Aarron Walter, author of "Designing for Emotion", has applied Maslow's hierarchy of needs to design the emotional design pyramid (Figure 8).

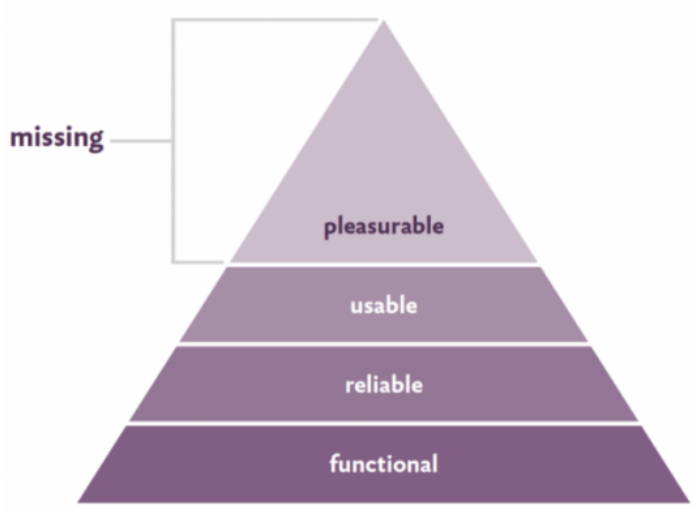

Figure 8: Aarron Walter's emotional design pyramid

Note. This image was created to present the unfulfilled emotional design. From Aarron Walter. (2011). Designing for Emotion, A Book Apart

According to his pyramid, most of today's designs often exclude the top of the pyramid which is the pleasurable or satisfaction experience with the product. In order to strive for the top of this pyramid, this paper applies the Kano Model approach to ensure the playful use of the product. The Kano model process involves the data of potential users on how they feel different product elements can affect their satisfaction or dissatisfaction, especially when a feature is present or absent. The result of Kano model analysis is based on the priority of the essential features, assumed from its five categories, which are: Attractive, Performance, Must-be, Indifferent, and Reverse. However, according to "The Complete Guide to the Kano Model" (DANIEL ZACARIAS, n.d.), there is a sixth category, the Questionable, of which purpose is to verify human mistakes during the data collection.

Specifically, the Attractive represents the features that may not cause users dissatisfaction if they were missed but users would be delighted if this type of feature was included. The Must-be category is the basic features that users expected from the product. Its inclusion does not increase users satisfaction but would cause greater dissatisfaction as they feel the product is not as it is. A Must-be feature sometimes described as the Linear or One-Dimensional, the Performance category is in between the $\mathrm{X}$ and $\mathrm{Y}$ axis (Satisfaction and Functionality). The Performance-related features work as users intuitively think of how satisfaction works: the more provided, the more satisfied the users would be. Users would not care about Indifferent features as it would not make any difference to users' reaction towards the products. The Reverse and Questionable assist the analysis steps as these categories exist to identify the conflict from the questionnaire's answers. For instance, the users do not like the functional feature, but they like it in the dysfunctional. From this case, it is assumed as Reverse while Questionable is for when the users like both functional and dysfunctional as they are not attentive. The order of the category should be Must-be at top, then Performance, followed by Attractive before the lowest which is Indifferent. 


\subsection{The Kano Model Questionnaire}

The implementation of the Kano questionnaire helps identify users' perception. The Kano model analysis determines the category of each feature among the 6 Kano Model's categories. The complete Kano Model consists of two Axes in which the X Axis determines whether the feature is functional or fully implemented while the Y Axis indicates the satisfaction level of the users with the feature. The making of Kano Model questionnaire involves the inclusion of the features or elements, the functional and its exclusion, the dysfunctional. The questionnaire is repeated in the structure of three questions for one element or feature starting with a functional question in which the feature or element is included, a dysfunctional question in which it is excluded and follow up with the importance.

The score of the answer options is based on the type of the question. For example, "I like it" for functional questions will be 4 while dysfunctional is -2 . The score ranged from $4,2,0,-1,-2$ respectively with "I like it!", "I expect it", "I'm neutral", "I can live with it", and "I dislike it" while the score ranged reversely of the same answer order.

The Kano question should not be too direct while users' feelings towards a feature play a key role to determine if it should exist within the product. Additionally, questions about the importance of the feature should be included as well. The score scale ranges from 0 to 9 . The questionnaire was developed to obtain information about the 17 game elements/features from the emotional design (Table 4) ranging from F1 to F17, resulting in a total of 51 questions and it was implemented to a sample of 30 participants.

\begin{tabular}{|c|c|}
\hline F1 & Risk-free interaction \\
\hline F2 & Scenario, Storytelling, Social problem reflection \\
\hline F3 & Distance travel while at home \\
\hline F4 & 3D environment for visiting \\
\hline F5 & Visit destinations inside Minecraft \\
\hline F6 & Virtual explore at any time \\
\hline F7 & Multiple people visit together/Multiplayer \\
\hline F8 & Co-work, co-share to build/rebuild/decorate virtual models \\
\hline F9 & Details close to real models \\
\hline F10 & Output device control to move in virtual world \\
\hline F11 & Move instantly cheat code \\
\hline F12 & Placing building instantly cheat code \\
\hline F13 & Euest, Reward \& Achievement System \\
\hline F14 & Extra decorative items/ options \\
\hline F15 & Disual quality enhancement close to realistic \\
\hline F16 & Dynamic auditory surrounding enhancement \\
\hline F17
\end{tabular}

Table 4: Game features and elements list for Kano Analysis

\subsection{The Kano Model Analysis}

The Kano Model analysis is divided into two steps: Discrete Analysis and Continuous Analysis. A discrete analysis divides the respondents into different backgrounds and adds up then categorizes each of the respondent's answers to the Kano model category in each feature. The continuous analysis provides a more in-depth analysis and often presents a more accurate view of what the users value and expected from the product. 


\subsubsection{Discrete Analysis}

The participants were separated based on their major background of Business, Design, and Engineer which respectively represent the Viability, Desirability and Usability to identify the most valuable design of this product (Figure 9).

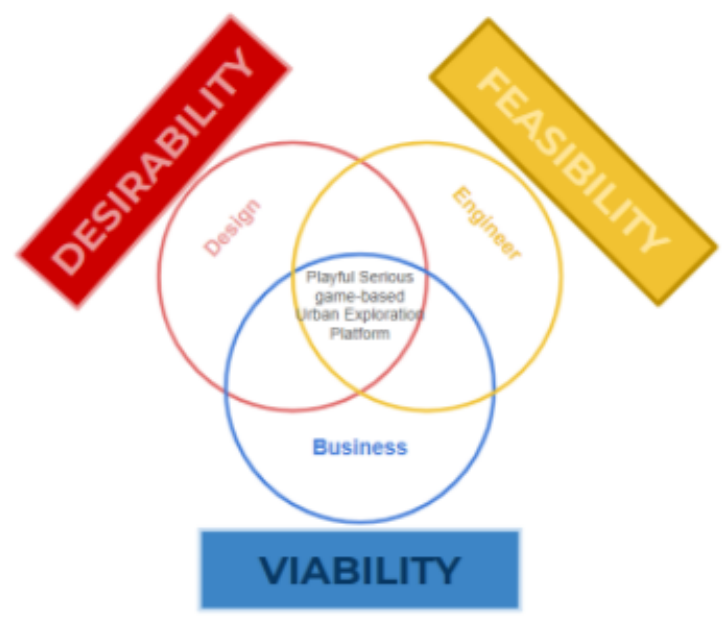

Figure 9: Trifecta for the most valuable design

The discrete analysis for three majors is presented in Table 5 and a general discrete analysis is presented in Table 5, Table 6, and Table 7. 


\begin{tabular}{|c|c|c|c|c|c|c|c|c|}
\hline \multicolumn{10}{|c|}{ BUSINESS } \\
\hline Feature & M & P & A & I & R & Q & Total & Category \\
\hline F1 & 14.29 & 0 & 28.57 & 42.85 & 0 & 14.29 & 100 & I \\
\hline F2 & 0 & 0 & 57.14 & 42.86 & 0 & 0 & 100 & A \\
\hline F3 & 0 & 0 & 28.57 & 57.14 & 0 & 14.29 & 100 & I \\
\hline F4 & 0 & 14.29 & 28.57 & 42.85 & 0 & 14.29 & 100 & I \\
\hline F5 & 0 & 14.29 & 57.14 & 28.57 & 0 & 0 & 100 & A \\
\hline F6 & 14.29 & 14.29 & 28.57 & 42.85 & 0 & 0 & 100 & I \\
\hline F7 & 28.57 & 0 & 28.57 & 14.29 & 14.29 & 14.28 & 100 & M \\
\hline F8 & 0 & 14.29 & 28.57 & 57.14 & 0 & 0 & 100 & I \\
\hline F9 & 0 & 42.85 & 14.29 & 28.57 & 0 & 14.29 & 100 & P \\
\hline F10 & 0 & 71.42 & 14.29 & 14.29 & 0 & 0 & 100 & P \\
\hline F11 & 0 & 0 & 28.57 & 57.14 & 0 & 14.29 & 100 & I \\
\hline F12 & 0 & 14.29 & 0 & 71.42 & 14.29 & 0 & 100 & I \\
\hline F13 & 0 & 0 & 0 & 57.14 & 42.86 & 0 & 100 & I \\
\hline F14 & 0 & 14.29 & 57.14 & 28.57 & 0 & 0 & 100 & A \\
\hline F15 & 0 & 0 & 57.14 & 42.86 & 0 & 0 & 100 & A \\
\hline F16 & 0 & 0 & 28.57 & 57.14 & 14.29 & 0 & 100 & I \\
\hline F17 & 14.29 & 0 & 14.29 & 71.42 & 0 & 0 & 100 & I \\
\hline
\end{tabular}

Table 5: Discrete analysis table for Business Perspective

\begin{tabular}{|c|c|c|c|c|c|c|c|c|}
\hline \multicolumn{10}{|c|}{ DESIGN } \\
\hline Feature & M & P & A & I & R & Q & Total & Category \\
\hline F1 & 12.5 & 6.25 & 18.75 & 43.75 & 6.25 & 12.5 & 100 & I \\
\hline F2 & 0 & 12.5 & 56.25 & 18.75 & 0 & 12.75 & 100 & A \\
\hline F3 & 0 & 6.25 & 50 & 31.25 & 6.25 & 6.25 & 100 & A \\
\hline F4 & 0 & 6.25 & 56.25 & 18.75 & 12.5 & 6.25 & 100 & A \\
\hline F5 & 0 & 18.75 & 43.75 & 31.25 & 0 & 6.25 & 100 & A \\
\hline F6 & 0 & 31.25 & 37.5 & 25 & 0 & 6.25 & 100 & A \\
\hline F7 & 6.25 & 25 & 18.75 & 18.75 & 12.5 & 18.75 & 100 & P \\
\hline F8 & 0 & 25 & 25 & 25 & 12.5 & 12.5 & 100 & P \\
\hline F9 & 31.25 & 0 & 50 & 18.75 & 0 & 0 & 100 & A \\
\hline F10 & 6.25 & 37.5 & 18.75 & 25 & 0 & 12.5 & 100 & P \\
\hline F11 & 0 & 12.5 & 43.75 & 31.25 & 12.5 & 0 & 100 & A \\
\hline F12 & 0 & 18.75 & 43.75 & 31.25 & 0 & 6.25 & 100 & A \\
\hline F13 & 0 & 0 & 25 & 56.25 & 12.5 & 6.25 & 100 & I \\
\hline F14 & 0 & 31.25 & 31.25 & 25 & 6.25 & 6.25 & 100 & P \\
\hline F15 & 0 & 18.75 & 62.5 & 6.25 & 6.25 & 6.25 & 100 & A \\
\hline F16 & 12.5 & 12.5 & 62.5 & 12.5 & 0 & 0 & 100 & A \\
\hline F17 & 0 & 62.5 & 50 & 18.75 & 6.25 & 18.75 & 100 & A \\
\hline
\end{tabular}

Table 6: Discrete analysis table for Design Perspective 


\begin{tabular}{|c|c|c|c|c|c|c|c|c|}
\hline \multicolumn{10}{|c|}{ ENGINEER } \\
\hline Feature & M & P & A & I & R & Q & Total & Category \\
\hline F1 & 14.29 & 0 & 28.57 & 57.14 & 0 & 0 & 100 & I \\
\hline F2 & 0 & 28.57 & 42.85 & 14.29 & 0 & 14.29 & 100 & A \\
\hline F3 & 14.29 & 28.57 & 14.28 & 28.57 & 0 & 14.29 & 100 & P \\
\hline F4 & 0 & 14.29 & 42.85 & 28.57 & 0 & 14.29 & 100 & A \\
\hline F5 & 0 & 0 & 28.57 & 57.14 & 0 & 14.29 & 100 & I \\
\hline F6 & 0 & 14.29 & 28.57 & 42.85 & 0 & 0 & 100 & I \\
\hline F7 & 0 & 0 & 57.14 & 28.57 & 0 & 14.29 & 100 & A \\
\hline F8 & 14.29 & 0 & 28.57 & 28.57 & 0 & 28.57 & 100 & A \\
\hline F9 & 0 & 28.57 & 28.57 & 28.57 & 0 & 14.29 & 100 & P \\
\hline F10 & 0 & 28.57 & 14.29 & 42.85 & 0 & 14.29 & 100 & I \\
\hline F11 & 14.29 & 28.57 & 28.57 & 28.57 & 0 & 0 & 100 & P \\
\hline F12 & 0 & 0 & 28.57 & 57.14 & 0 & 14.29 & 100 & I \\
\hline F13 & 0 & 0 & 42.85 & 42.85 & 0 & 14.3 & 100 & A \\
\hline F14 & 14.29 & 57.13 & 0 & 14.29 & 0 & 14.29 & 100 & P \\
\hline F15 & 0 & 28.57 & 28.57 & 42.86 & 0 & 0 & 100 & I \\
\hline F16 & 0 & 0 & 28.57 & 14.29 & 57.14 & 0 & 100 & I \\
\hline F17 & 0 & 14.29 & 28.57 & 57.14 & 0 & 0 & 100 & I \\
\hline
\end{tabular}

Table 7: Discrete analysis table for Engineer Perspective

The data obtained here give a determining perspective to differentiate the opinion of the users about the features, while focusing on their common ones helps prioritize the features for a better service design. As can be seen from Table 5, the common features from three different perspectives that are viewed as valuable are F1 and F2 - the risk free interaction and scenario, storytelling, social problem reflection although the F1 is considered as Indifferent while F2 is Attractive. Although initially it was sought to obtain similar results for Performance and Must-be features in common, Business major viewed F7 as Must-be, F9 and F10 as Performance. On the other majors, Design viewed F7, F8, F10, and F14 as Performance while most of the rest are Attractive while Engineer viewed F3, F9, F11, and F14 as Performance. Perspectively, F7, F9, F10 and F14 are noticeable features as two out of three majors viewed them as a more significant feature than the others. Nevertheless, from a general view (Table 8), the result displays that only F10 and F14 are the Performance feature which determine the interaction of a game and the importance of the implementation of goal-oriented systems such as Quest, Reward, and Achievement in instinctively motivating the users. 


\begin{tabular}{|c|c|c|c|c|c|c|c|c|}
\hline \multicolumn{10}{|c|}{ GENERAL } \\
\hline Feature & M & P & A & I & R & Q & Total & Category \\
\hline F1 & 13.33 & 3.33 & 23.34 & 46.687 & 3.33 & 10 & 100 & I \\
\hline F2 & 0 & 13.33 & 53.33 & 23.34 & 0 & 10 & 100 & A \\
\hline F3 & 3.33 & 10 & 36.67 & 36.67 & 3.33 & 10 & 100 & A \\
\hline F4 & 0 & 10 & 46.67 & 26.67 & 6.66 & 10 & 100 & A \\
\hline F5 & 0 & 13.33 & 43.33 & 36.67 & 0 & 6.67 & 100 & A \\
\hline F6 & 3.33 & 23.34 & 33.33 & 33.33 & 0 & 6.67 & 100 & A \\
\hline F7 & 10 & 13.33 & 30 & 20 & 10 & 16.67 & 100 & A \\
\hline F8 & 3.33 & 16.67 & 26.67 & 33.33 & 6.67 & 13.33 & 100 & I \\
\hline F9 & 16.67 & 16.67 & 36.67 & 23.33 & 0 & 6.66 & 100 & A \\
\hline F10 & 3.33 & 43.33 & 16.67 & 26.67 & 0 & 10 & 100 & P \\
\hline F11 & 3.33 & 13.33 & 36.67 & 36.67 & 6.67 & 3.33 & 100 & A \\
\hline F12 & 0 & 13.33 & 30 & 46.67 & 3.33 & 6.67 & 100 & I \\
\hline F13 & 0 & 0 & 23.33 & 53.33 & 16.67 & 6.67 & 100 & I \\
\hline F14 & 3.33 & 33.33 & 30 & 23.34 & 3.33 & 6.67 & 100 & P \\
\hline F15 & 0 & 16.67 & 53.33 & 23.34 & 3.33 & 3.33 & 100 & A \\
\hline F16 & 6.67 & 13.33 & 43.34 & 33.33 & 3.33 & 0 & 100 & A \\
\hline F17 & 3.33 & 6.67 & 36.67 & 40 & 3.33 & 10 & 100 & I \\
\hline
\end{tabular}

Table 8: General Discret Analysis Table

\subsubsection{Continuous analysis}

The continuous analysis provides more insight to the users' satisfaction than the discrete table as of the inclusion of the average value of users' satisfaction, dissatisfaction and the importance of features. This analysis also presents the data visualisation of the data in (Table 9) to visualize onto the Kano Model Graph (Figure 10) 


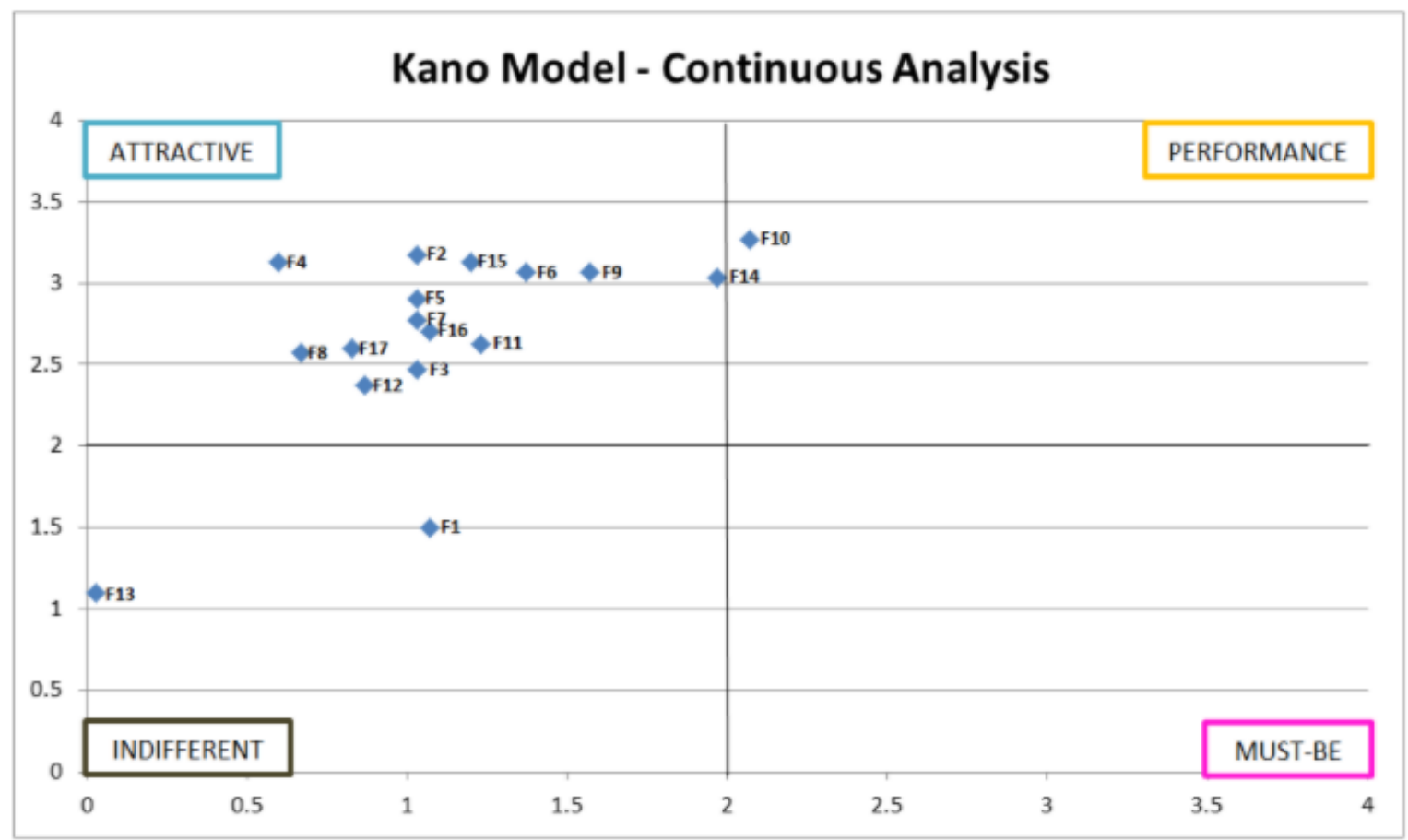

Figure 10: The Kano Model Graph

\begin{tabular}{|c|c|c|c|c|}
\hline Feature & Dysfunctional(X) & Functional(Y) & Importance(Z) & Category \\
\hline F1 & 1.07 & 1.5 & 6.77 & $\mathrm{I}$ \\
\hline F2 & 1.03 & 3.17 & 7.03 & $\mathrm{~A}$ \\
\hline F3 & 1.03 & 2.47 & 6.53 & $\mathrm{~A}$ \\
\hline F4 & 0.6 & 3.13 & 6.73 & $\mathrm{~A}$ \\
\hline F5 & 1.03 & 2.9 & 6.93 & $\mathrm{~A}$ \\
\hline F6 & 1.37 & 3.07 & 7.2 & $\mathrm{~A}$ \\
\hline F7 & 1.03 & 2.77 & 7.43 & $\mathrm{~A}$ \\
\hline F8 & 0.67 & 2.57 & 7 & $\mathrm{~A}$ \\
\hline F9 & 1.57 & 3.07 & 7.23 & $\mathrm{~A}$ \\
\hline F10 & 2.07 & 3.27 & 7.37 & P \\
\hline F11 & 1.23 & 2.63 & 7.1 & $\mathrm{~A}$ \\
\hline F12 & 0.87 & 2.37 & 6.5 & $\mathrm{~A}$ \\
\hline F13 & 0.03 & 1.1 & 5.63 & $\mathrm{I}$ \\
\hline F14 & 1.97 & 3.03 & 7.5 & $\mathrm{~A}$ \\
\hline F15 & 1.2 & 3.13 & 7.2 & $\mathrm{~A}$ \\
\hline F16 & 1.07 & 2.7 & 7.27 & $\mathrm{~A}$ \\
\hline F17 & 0.83 & 2.6 & 7.17 & $\mathrm{~A}$ \\
\hline
\end{tabular}

Table 9: Continuous Analysis Table 
The result of this analysis presents the top priority features users with both Kano Model category order is sorted based on the graph which also shows the value of the importance of each feature. Among the 17 features, F10 is Performance, F1, F13 are Indifferent while the rest are Attractive. The F14 that was Performance in Discret is now Attractive in Continuous Analysis. The result from the graph showing how close it is to the $\mathrm{X}$-axis. Apart from the Kano model graph, the result in Table 10 shows the complete sorting of 17 features based on the Kano Model category order and feature importance. Based on the categories, the top three elements are F10, F14, and F7 ranking respectively, which are the ability to control with output devices, the Quest, Reward, Achievement systems and Multiplayer. The three elements also stay at the top from the importance side, but the ranking swap with F14 stays at the top, scoring 7.5 before F7-7.43 and F10-7.37. Additionally, aside from the top three features, the bottom three provide another perspective of the users to the proposed features that the designers should avoid and not to overinvest in these features. In the category order in Table 8, the bottom three features are F13, F1 and F12 which are placing buildings instantly with cheat code, risk-free interaction, and move instantly with cheat code. In the importance order in Table 8, the bottom three features are F13, F12, and F3 in which F3 is distance travel at home. The results from Table 10 indicates that users would prefer to face the challenges inside the game without the need of cheat codes while they would also prefer to explore a destination physically.

\begin{tabular}{|c|c|}
\hline Category Order & Importance Order \\
\hline F & F14 \\
\hline F14 & F7 \\
\hline F7 & F10 \\
\hline F16 & F16 \\
\hline F9 & F9 \\
\hline F15 & F15 \\
\hline F6 & F6 \\
\hline F17 & F17 \\
\hline F11 & F11 \\
\hline F2 & F2 \\
\hline F8 & F8 \\
\hline F5 & F5 \\
\hline F4 & F1 \\
\hline F3 & F4 \\
\hline F12 & F3 \\
\hline F1 & 12 \\
\hline F13 & F13 \\
\hline
\end{tabular}

Table 10: Continuous Analysis results, sorting from Category and Importance

\section{Conclusion}

In this paper, the author proposed the game elements and features to prioritize designing a serious gamebased urban exploration and proof of concept from adopting digital twins. The Kano Model results show that users prefer a platform to interact and control their character instead of simply observing. Additionally, a co-op environment with challenging and rewarding systems like Quest, Reward and, Achievement would motivate them in a playful urban exploration simulation. Furthermore, the result shows that players prefer to 
enjoy the gameplay, having some challenges instead of using cheat code, although the author still believes that the cheat code would assist users who lack skill and time. The proposed serious game for urban exploration can provide an alternative vision to the sustainable Smart City development to engage citizens, provide them the architecture and spatial knowledge. The digital twin concept helps build a more realistic virtual twin of physical destinations. Based on this concept principle, players and citizens can develop their preferable version of the urban areas. The author firmly believes that Don Norman's three levels of emotional design provide a perception in design games as products that serve not just players. However, the current progress has not yet implemented Quest mod packs to create scenarios and goals; hence, the next step of this research is to focus on implementing one to utilize the digital twin purpose and cooperate citizens during the pandemic period. The future work will also include documentation of gameplay sessions and record users' awareness of space, scenarios, and decision-making.

\section{References}

[1] Aarron Walter. (2011). Designing for Emotion. A Book Apart

[2] Abt, C. (1969). Serious Games. New York: Viking Press

[3] Ampatzidou, C., \& Gugerell, K. (2019). Mapping game mechanics for learning in a serious game for the energy transition. International Journal of E-Planning Research (IJEPR), 8(2), 1-23.

[4] Ampatzidou, C., Gugerell, K., Constantinescu, T., Devisch, O., Jauschneg, M., Berger, M., 2018. All Work and No Play? Facilitating Serious Games and Gamified Applications in Participatory Urban Planning and Governance. Urban Planning 3, 34-46.. doi:10.17645/up.v3i1.1261

[5] ANZLIC. (n.d.). Principles for Spatially Enabled Digital Twins of the Built and Natural Environment in Australia. https://www.anzlic.gov.au/resources/principles-spatially-enabled-digital-twins-built-andnatural-environment-australia Accessed: 9th April, 2021

[6] Baharom, S. N., Tan, W. H., \& Idris, M. Z. (2014). Emotional design for games: A framework for player-centric approach in the game design process. International Journal of Multimedia and Ubiquitous Engineering, 9(10), 387-398.

[7] Baños, R. M., Botella, C., Alcañiz, M., Liaño, V., Guerrero, B., \& Rey, B. (2004). Immersion and emotion: their impact on the sense of presence. Cyberpsychology \& behavior, 7(6), 734-741.

[8] Boschert, S., \& Rosen, R. (2016). Digital Twin-The Simulation Aspect. In (pp. 59-74): Springer International Publishing.

[9] Centers of Disease Control and Prevention. (2020, April 2). About Variants of the Virus that Causes COVID-19. https://www.cdc.gov/coronavirus/2019-ncov/transmission/variant.html Accessed: 9th April, 2021

[10] Cocar, M., Harris, R., Khmelevsky, Y., 2017. Utilizing Minecraft bots to optimize game server performance and deployment, in: .. doi:10.1109/ccece.2017.7946694

[11] Colley, R. C., Bushnik, T., \& Langlois, K. (2020). Exercise and screen time during the COVID-19 pandemic. Health Reports, 31(6), 3-11.

[12] De', R., Pandey, N., \& Pal, A. (2020). Impact of digital surge during Covid-19 pandemic: A viewpoint on research and practice. International Journal of Information Management, 102171. doi:10.1016/j.ijinfomgt.2020.102171 
[13] Dembski, F., Wössner, U., Letzgus, M., Ruddat, M., \& Yamu, C. (2020). Urban Digital Twins for Smart Cities and Citizens: The Case Study of Herrenberg, Germany. Sustainability, 12(6), 2307. doi:10.3390/su12062307

[14] Deren, L., Wenbo, Y., Zhenfeng, S., 2021. Smart city based on digital twins. Computational Urban Science 1.. doi:10.1007/s43762-021-00005-y

[15] El Saddik, A. (2018). Digital Twins: The Convergence of Multimedia Technologies. IEEE MultiMedia, 25(2), 87-92. doi:10.1109/mmul.2018.023121167

[16] Elmerghany, A. H., \& Paulus, G. (2017). Using Minecraft as a geodesign tool for encouraging public participation in urban planning. GI_Forum 2017, 5 300-314.

[17] Fauzan, N., sophian Shminan, A., \& Binit, A. J. A. (2018). The Effects of Minecraft Videogame On Creativity. International Journal of Engineering\& Technology, 7(3.22), 42-44.

[18] Ghasemaghaei, R., Arya, A., Biddle, R., 2017. Affective Walkthroughs and Heuristics: Evaluating Minecraft Hour of Code, in: Information Security and Privacy. Information Security and Privacy, pp. $22-40$.

[19] Gugerell, K., Jauschneg, M., Platzer, M., \& Berger, M. (2017, September). Playful Participation with Urban Complexity-Evaluation of the Co-Located Serious Game Mobility Safari in Vienna. In REAL CORP 2017-PANTA RHEI-A World in Constant Motion. Proceedings of 22nd International Conference on Urban Planning, Regional Development and Information Society (pp. 413-420).

[20] Hang M (Feb, 2020) Preparing cities for epidemics: Lessons from the COVID19 outbreak. The Urban Now: International Journal of Urban and Regional Research 2020

[21] Hewett, K., Zeng, G., \& Pletcher, B. (2020). The Acquisition of 21 st-Century Skills Through Video Games: Minecraft Design Process Models and Their Web of Class Roles. Simulation \& Gaming.

[22] HUIZINGA, J. Homo Ludens: A Study of the Play-Element in Culture. Routledge Chapman \& Hall, 1999.

[23] Ivanova, M., Ivanov, I. K., \& Ivanov, S. (2021). Travel behaviour after the pandemic: the case of Bulgaria. Anatolia, 32(1), 1-11. doi:10.1080/13032917.2020.1818267

[24] Lew, A. A., Cheer, J. M., Haywood, M., Brouder, P., \& Salazar, N. B. (2020). Visions of travel and tourism after the global COVID-19 transformation of 2020. Tourism Geographies, 22(3), 455-466. doi:10.1080/14616688.2020.1770326

[25] Norman, D. (2003). The design of everyday things. Basic books.

[26] Osterman KF (1998) Using Constructivism and Reflective Practice To Bridge the Theory/Practice Gap. American Educational Research Association, San Diego

[27] Poplin, A. (2012). Playful public participation in urban planning: A case study for online serious games. Computers, environment and urban systems, 36(3), 195-206.

[28] Predescu, A., \& Mocanu, M. (2019, June). Increasing collaboration and participation through serious gaming for improving the quality of service in urban water infrastructure. In International Conference on Business Information Systems (pp. 585-596). Springer, Cham. 
[29] Ravyse, W. S., Blignaut, A. S., Leendertz, V., \& Woolner, A. (2017). Success factors for serious games to enhance learning: a systematic review. Virtual Reality, 21(1), 31-58.

[30] Riemer, K., Seymour, M., 2021. Virtual Visitation: Conceptualization and Metrics for Digital Twinning of Large Interactive Social Events, in: .. doi:10.24251/hicss.2021.546

[31] Salama, A.M., 2020. Coronavirus questions that will not go away: interrogating urban and sociospatial implications of COVID-19 measures. Emerald Open Research.

[32] Scheller, C., Schraner, Y., \& Vogel, M. (2020). Sample Efficient Reinforcement Learning through Learning from Demonstrations in Minecraft.

[33] Scholten, H., 2017. Geocraft as a Means to Support the Development of Smart Cities, Getting the People of the Place Involved - Youth Included -. Quality Innovation Prosperity.

[34] Schrotter, G., \& Hürzeler, C. (2020). The Digital Twin of the City of Zurich for Urban Planning. PFG - Journal of Photogrammetry, Remote Sensing and Geoinformation Science, 88(1), 99-112. doi:10.1007/s41064-020-00092-2

[35] Shafto M, Conroy M, Doyle R, Glaessgen E, Kemp C, LeMoigne J, Wang L (2012) NASA technology roadmap: modeling, simulation, information technology \& processing roadmap technology area 11, Apr 2012

[36] Taiwan Centers of Disease Control. (2021). [COVID-19 New Daily Cases].https://www.cdc.gov.tw/En Accessed: 9th April, 2021

[37] Von Der Heiden, J.M., Braun, B., Müller, K.W., Egloff, B., 2019. The Association Between Video Gaming and Psychological Functioning. Frontiers in Psychology.

[38] Wang, Z. (2020). Digital Twin Technology. In Industry 4.0-Impact on Intelligent Logistics and Manufacturing. IntechOpen.

[39] Wong, C.W., Tsai, A., Jonas, J.B., Ohno-Matsui, K., Chen, J., Ang, M., Ting, D.S.W., 2021. Digital Screen Time During the COVID-19 Pandemic: Risk for a Further Myopia Boom?. American Journal of Ophthalmology 223, 333-337.. doi:10.1016/j.ajo.2020.07.034

[40] Yogman, M., Garner, A., Hutchinson, J., Hirsh-Pasek, K., Golinkoff, R.M., 2018. The Power of Play: A Pediatric Role in Enhancing Development in Young Children. Pediatrics 142, e20182058.. doi:10.1542/peds.2018-2058 